\title{
Stability of roof trusses stiffened by trapezoidal sheeting and purlins
}

\author{
Natalia Korcz-Konkol ${ }^{1, *}$, and Piotr Iwicki ${ }^{1}$ \\ ${ }^{1}$ Gdańsk University of Technology, Faculty of Civil and Environmental Engineering, Narutowicza \\ 11/12, 80-233 Gdańsk, Poland
}

\begin{abstract}
In the article linear buckling analysis of a set of steel trusses braced by purlins and trapezoidal sheeting are conducted. The buckling load factor due to the height of a corrugated sheeting profile is investigated in parametric studies. The minimal height of trapezoidal sheeting required for preventing the sheeting and chords of the trusses against the buckling is obtained. Two groups of models are considered: "axial" model as a simple one and "eccentric" model as a more complex one. In the second group of models, eccentricity between the top chord of the trusses and purlins is considered, by means of equivalent beam elements. The differences between models are indicated and the results are discussed.
\end{abstract}

\section{Introduction}

It is well-known that sheeting can stabilize purlins against distortional buckling [1]. Additionally, according to [2], if fastening of the sheeting to the structure meets specific requirements, it can be considered as the diaphragm, which affects the stiffness and spatial character of work of the structure and, by extension, deflections and cross-sectional forces of particular structural members. As a result, the corrugated sheets of a roof apart from bearing vertical loads are part of bracing which stabilizes not only purlins but also an entire structure, e.g. roof trusses. Large research has been conducted on bracing requirements or effect of corrugated sheeting stiffness on buckling load of various elements of structures (e.g. purlin, top chord of the truss) connected directly to sheeting, as e.g. $[3,4,5,6]$. The problem of bracing requirements of trusses was also investigated in experimental research [7, 8]. In [9] the influence of the diaphragm effect on the behaviour of portal frames with purlins and cladding was analysed.

The present research focused on the buckling study of a set of the trusses stiffened by purlins and trapezoidal sheets. The aim is to find parameters of the roof diaphragm (the height of the trapezoidal sheet profile) which stabilize the cladding and the chords of the trusses against buckling. The eigenvalue problem is solved in order to obtain the roof buckling load factor. The influence of the corrugated sheeting and the purlins on buckling load factor of the roof is observed. Additionally, the differences in two groups of models of the roof (simple and complex one) are indicated.

\footnotetext{
*Corresponding author: natkorc1@pg.edu.pl
} 
Two-side fastening of the sheeting (instead of four-side fastening) is taken into account, in the case of roofs with purlins it occurs more frequently in engineering practice. The sheeting is fastened to the purlins, which rest on the top chords of the trusses. There is no direct connection between sheeting and trusses except the connection with gable trusses, which is performed using special elements, the so-called shear connectors.

\section{Structure description}

The roof shown in Fig. 1 and Fig. 3 is considered in the parametric analysis. The model was built following the structure studied in [5]. The main structural elements of the roof are five $24 \mathrm{~m}$ long trusses with the depth in the middle equal to $1,61 \mathrm{~m}$. Truss chords and two compressed diagonals near the supports are made of $2 \mathrm{~L}$ profiles (top chord - $2 \mathrm{~L}$ $90 \times 90 \times 9$, bottom chord $-2 \mathrm{~L} 80 \times 80 \times 8$ and two diagonals $-2 \mathrm{~L} 65 \times 65 \times 7$ ). Other diagonals consist of U65 profile. The truss spacing is $6 \mathrm{~m}$. Roof decking made of trapezoidal sheets rests on Z-purlins located every second truss joint (2,4 m spacing, Z $250 \times 60 \times 2$ profile). The geometry of the trapezoidal cladding profile is presented in Fig. 2. It was assumed that the height $h$ of the corrugated sheeting profile may vary between $20 \mathrm{~mm}$ and $70 \mathrm{~mm}$, other geometric parameters are constant.

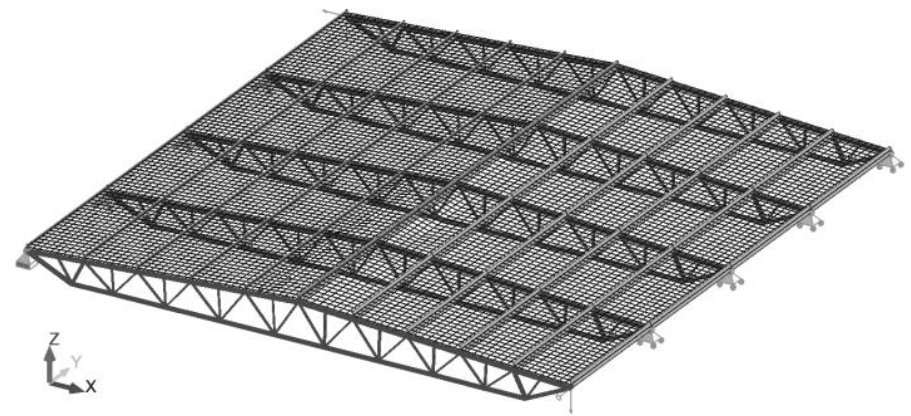

Fig. 1. Roof structure - axonometric view.

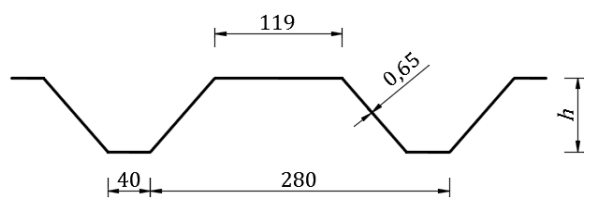

Fig. 2. Trapezoidal sheeting geometry $[\mathrm{mm}]$.

\section{Numerical model}

Linear buckling analyses of the roof are carried out by means of program Robot Structural Analysis Professional [10]. Truss chords and purlins are applied in numerical models as spatial beam elements with six degrees of freedom in node. The connections between truss elements are rigid except the diagonals that are connected to the truss chords by in-plane hinges. Corrugated sheets are substituted by equivalent orthotropic shell elements. 
Trusses, as parts of a single-storey steel building, are supported according to the scheme presented in Fig. 3. The load, corresponding to self weight and snow, is applied on the sheeting surface in vertical direction with the value $1.74 \mathrm{kN} / \mathrm{m}^{2}$.

Two groups of models are built: the first group with sheeting, purlins and top chord of the trusses modelled at the same plane ("axial" models) and the second group distinguishing the levels of the roof elements ("eccentric" models).

In the "eccentric" models the approach based on $[11,12]$ is adopted in order to include the fact of two sides fastening of the sheeting. Equivalent spatial beam elements are implemented with the length corresponding to the eccentricity between the top chord of the truss axis and purlin axis (see Fig. 4). Element with the length of $160 \mathrm{~mm}$ is applied. The sheeting is connected directly to purlins (in the axis plane, without any eccentricity included). The spacing of the nodes connecting purlins and sheets corresponds to the spacing of the purlin-sheeting fasteners (case of fastening in every corrugation is taken into consideration). As a result, two layers of the roof structure are built. Cantilevered elements are applied, with rigid connection to the truss top chords and with hinged connection to the purlins (axial and truss-in-plane rotation is released). The scheme of the releases is the result of the approximation of the connection detail of the top chord of the truss ( $2 \mathrm{~L}$ profile), the purlin ( $\mathrm{Z}$ profile) and the sheeting. In the present study flexibility of the fasteners and connections are not included. The cross-section of the equivalent element is not calculated, the rigid profile is chosen (HEA 100 profile).

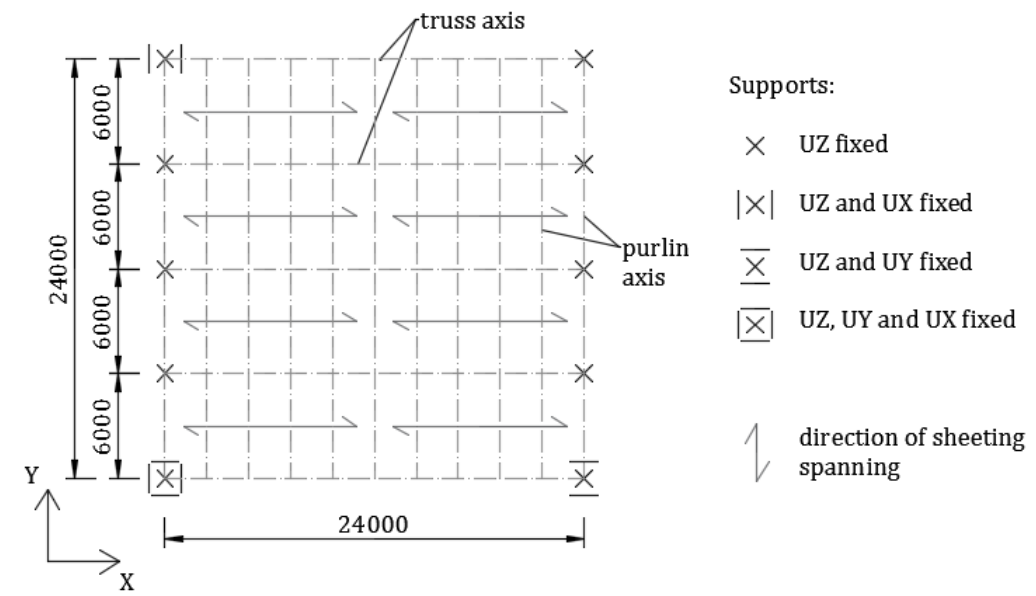

Fig. 3. Roof structure - static scheme [mm].

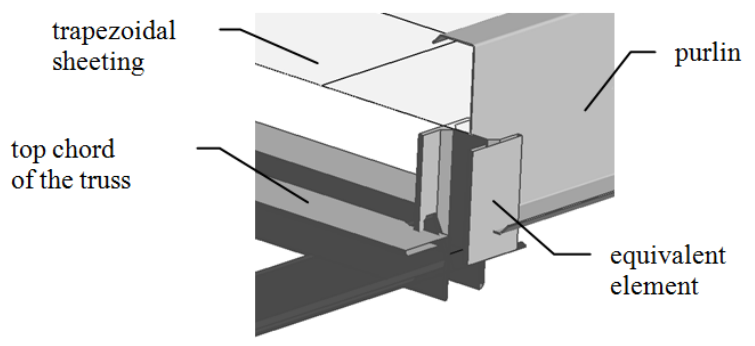

Fig. 4. Detail of the eccentricity connection (top chord - purlin - sheeting).

Substitution trapezoidal sheeting by the equivalent orthotropic shell model is performed using a tool implemented in ARSA software. This tool, available also in many other computational programs for numerical 3D analyses of the structures, computes the stiffness 
matrix terms based on the trapezoidal plate geometry selected by the user (the user is not obliged to calculate the matrix terms himself [10]. Obviously, this approach is only an approximation. This issue is widely discussed in $[13,14,15]$.

\section{Results of numerical simulations}

The values of the roof buckling load factor due to the height of the corrugated sheeting, obtained for both "axial" and "eccentric" models, are presented in Table 1 and Fig. 5. Samples of the buckling modes corresponding to the lowest values of buckling load acting downward are presented in Fig. 6a-c.

Table 1. Buckling load factor $\lambda$ of the roof due to the height of the corrugated sheeting.

\begin{tabular}{|c|c|c|c|c|}
\hline \multirow{2}{*}{$\begin{array}{c}\text { The height } \boldsymbol{h} \\
\text { of the sheeting } \\
{[\mathbf{m m}]}\end{array}$} & \multicolumn{2}{|c|}{ "Axial" model } & \multicolumn{2}{c|}{ "Eccentric" model } \\
\cline { 2 - 5 } & $\begin{array}{c}\text { Buckling load } \\
\text { factor } \boldsymbol{\lambda}\end{array}$ & $\begin{array}{c}\text { Buckled } \\
\text { element }\end{array}$ & $\begin{array}{c}\text { Buckling load } \\
\text { factor } \boldsymbol{\lambda}\end{array}$ & $\begin{array}{c}\text { Buckled } \\
\text { element }\end{array}$ \\
\hline 20 & 0,48 & sheet & 0,42 & sheet \\
\hline 25 & 0,75 & sheet & 0,65 & sheet \\
\hline 30 & 1,08 & sheet & 0,94 & sheet \\
\hline 35 & 1,25 & diagonal & 1,28 & sheet \\
\hline 40 & 1,25 & diagonal & 1,49 & diagonal \\
\hline 70 & 1,25 & diagonal & 1,49 & diagonal \\
\hline
\end{tabular}

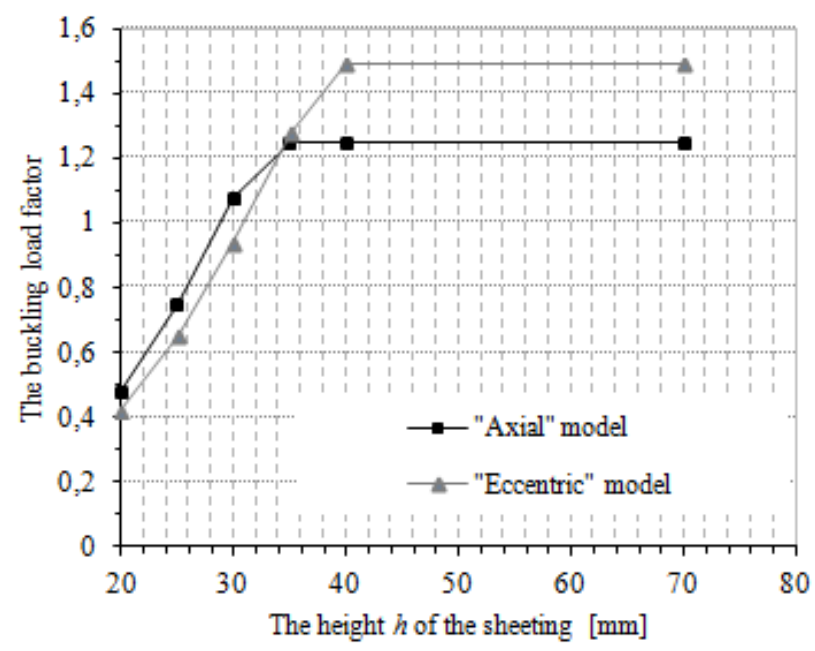

Fig. 5. The buckling load factor $\lambda$ of the roof due to the height of the corrugated sheeting.

The increase of the buckling load of the roof with the increase of corrugated sheet height was observed in both groups of models. For "eccentric" models it was also found that for sheets with the height $40 \mathrm{~mm}$ and higher the critical load does not increase (in the case of "axial" model it occurred for sheets $35 \mathrm{~mm}$ high). Minimal depth of the roof decking required for stabilization of the roof is therefore $40 \mathrm{~mm}$ according to "eccentric" models and $35 \mathrm{~mm}$ according to "axial" models. The buckling mode for a $40 \mathrm{~mm}$ high cladding corresponding to downward loading is presented in Fig. 6c. Buckling of the 
compressed U-profile diagonal occurred. Further increase of buckling load can be achieved increasing the cross-section of this diagonal.

The results of present studies can be compared to the results obtained in [5], where the same trusses were analysed, but in a slightly different support scheme and with the cladding system without purlins (instead of a purlin roof structure). In this case the minimal height of the roof cladding required for stabilization of the truss was $50 \mathrm{~mm}$.

The lowest values of buckling load for corrugated decking with the profile higher than $30 \mathrm{~mm}$ in case of "eccentric" model (and $25 \mathrm{~mm}$ in case of "axis" model) correspond to upward loading of the roof caused e.g. by wind suction.

Fig. 5 shows the difference between the results obtained for two groups of models. As long as the sheeting is the crucial element in the light of buckling analyses, the "axial" model gives a higher buckling load factor than the "eccentric" model. It is induced by the fact that "axial" model does not consider two sides fastening of the sheeting (fastening only in two edges - to the purlins), which is accounted in "eccentric" models. Instead, when the diagonal begins to be the crucial element, the relation is opposite: the "axial" model gives lower buckling load factor than the "eccentric" model. It can be explained by the fact that the eccentricity of the connection between rafter and purlin included in a numerical model using equivalent element leads to the stiffness increase in the truss nodes. The diagonals buckle mainly in the truss plane, but also slightly out of plane. That can be the reason why the models with equivalent elements applied show the diagonals more rigidly supported compared to diagonals in "axial" models.
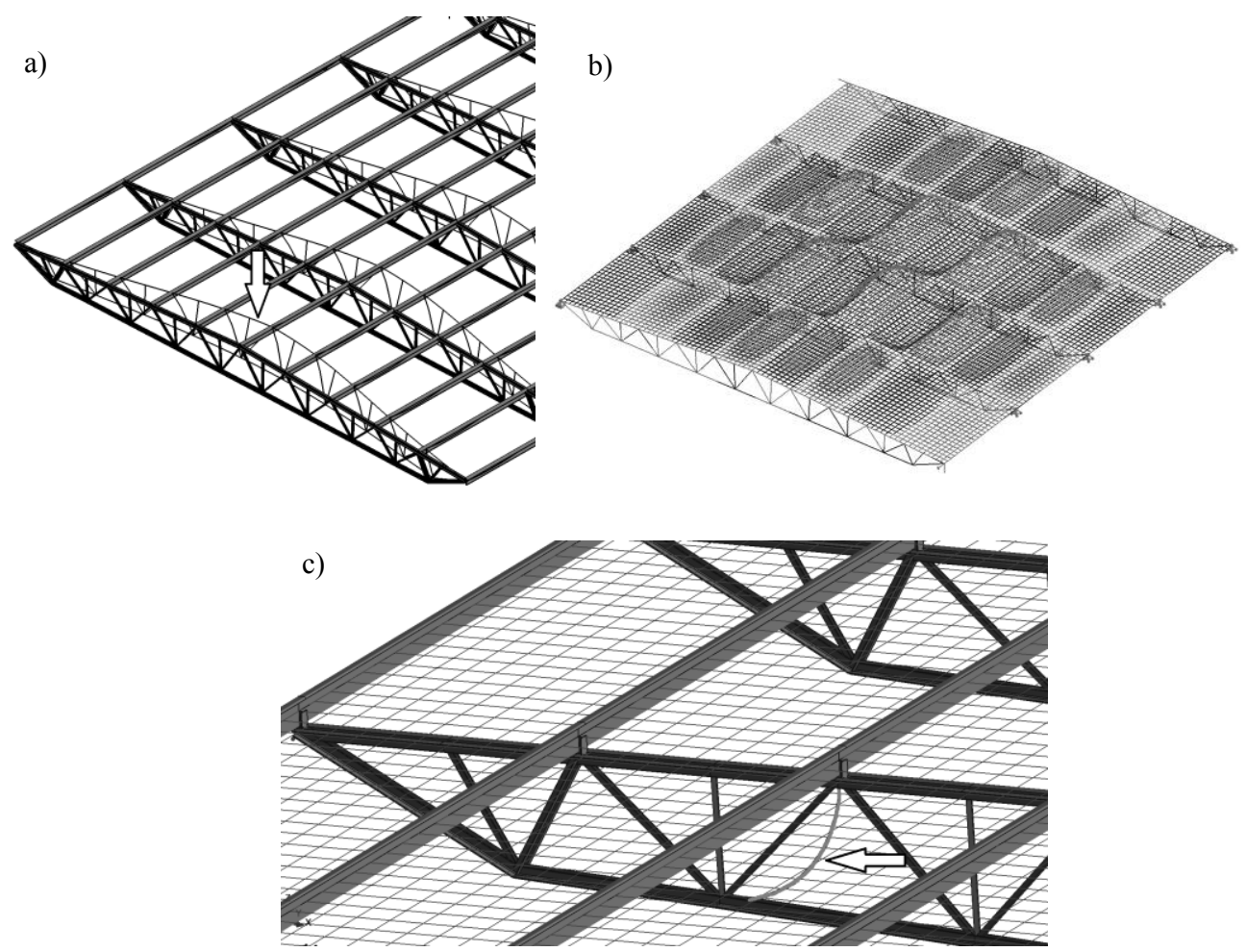

Fig. 6. The first buckling mode corresponding to: a) roof without trapezoidal sheeting ("eccentric" model, $\lambda=1,17), b)$ roof with trapezoidal sheeting $(h=30 \mathrm{~mm}$, "axial" model), c) roof with trapezoidal sheeting ( $h=40 \mathrm{~mm}$, "eccentric" model). 


\section{Conclusions}

The paper presents the results of stability studies on the set of trusses stiffened by purlins and corrugated cladding. In the parametric analysis of the roof a minimal height of the trapezoidal sheeting required for preventing the sheeting and the chords of the trusses against the buckling was obtained and the buckling load factor due to the height of the corrugated sheeting was investigated. Two groups of roof models ("axial" model as a simple one and "eccentric" model as a more complex one) were considered. Their differences were discussed consecutively.

As it was mentioned, applying trapezoidal sheeting by the equivalent orthotropic shell model and including the eccentricity of the members using equivalent spatial beam elements lead to approximation. In the second group of models, the eccentricity between the top chord of the trusses and the purlins is considered and the spacing of the nodes connecting sheeting and purlins corresponds to the spacing of the sheet - purlin fasteners. However, the flexibility of fasteners and connections, e.g. truss - purlin connection, purlin - sheets connection, seam fasteners (sheet - sheet connection) is omitted. Obtaining real flexibility of the connection and evaluation of the influence of them on the stability of the roof requires extra studies. Non-linear static analysis of an imperfect structure and shell model analysis of an entire structure are planned to verify the LBA results.

\section{References}

1. J. Bródka, R. Garncarek, K. Miłaczewski, Corrugated sheets in steel building (Arkady, Warszawa, 2009)

2. European Recommendations for the Application of Metal Sheeting Acting as a Diaphragm. Stressed Skin Design. ECCS - TC7, TWG 7.5 (1995)

3. B. Gosowski, Spatial stability of braced thin-walled members of steel structures, Journal of Constructional Steel Research, 59, 839-865 (2003)

4. A. Biegus, D. Wojczyszyn, Buckling length of chords out of the truss plane. Inżynieria i Budownictwo, 11/2004 (2004)

5. P. Iwicki, Stability of roof trusses stiffened by corrugated sheets, In W. Pietraszkiewicz, I. Kreja (Eds), Proceedings of the 9th SSTA Conference "Shell Structures. Theory and Applications, Vol. 2”, 113-116 (CRC Press/Balkema, 2010).

6. A. Biegus, Trapezoidal sheet as a bracing preventing flat trusses from out-of-plane buckling, Archives of Civil and Mechanical Engineering, 15, 735-741 (2015)

7. J. Jankowska-Sandberg, J. Kołodziej, Experimental study of steel truss lateraltorsional buckling, Engineering Structures, 46, 165-172 (2013)

8. M. Krajewski, P. Iwicki, Analysis of brace stiffness influence on stability of the truss, International Journal of Applied Mechanics and Engineering, 20, No.1, 97-108 (2015)

9. Zs. Nagy, A. Pop, I. Mois, R. Ballok, Stressed Skin Effect on the Elastic Buckling of Pitched Roof Portal Frames, Structures, 8, 227-244 (2016)

10. Robot Structural Analysis Professional, User Manual (Autodesk Inc 2015), http://help.autodesk.com/view/RSAPRO/2015/ENU/

11. J. Goczek, J. Juchniewicz, Ł. Supeł, Wplyw pionowego stężenia rygla petnościennego na zachowanie się ramy płaskiej. In M. A. Giżejowski et al. (Eds): Proceedings of the XIth ICMS "Progress in Steel, Composite and Aluminium Structures” (T\&F Group, 2006) 
12. M. Gryniewicz, J. K. Szlendak, FEM model of the steel building roof includes stressed skin diaphragm action effects, In M. A. Giżejowski et al. (Eds): Proceedings of The XIII ICMS "Recent Progress in Steel and Composite Structures" (CRC Press, 2016)

13. D. Wennberg, P. Wennhage, S. Stichel, Orthotropic Models of Corrugated Sheets in Finite Element Analysis, ISRN Mechanical Engineering, 2011, Art. ID 979532 (2011)

14. Y. Xia, M.I. Friswell, E.I. Saavedra Flores, Equivalent models of corrugated panels, International Journal of Solids and Structures, 49, 1453-1462 (2012)

15. N. Korcz, E. Urbańska-Galewska, Influence of fasteners and connections flexibility on deflections of steel building including the stressed skin effect, Technical Science, 21(2) (2018) 